\title{
Effects of Music Intervention Techniques on Very-Low- Birth-Weight Infants in Neonatal Intensive Care Unit: A Preliminary Study
}

Ji Yun Yun, $\mathrm{MD}^{1, *}$, Ji Sun Kim, MM, $\mathrm{MA}^{2,3, *}$, So-Yeon Shim, $\mathrm{MD}, \mathrm{PhD}^{1,2}$, Su Jin Cho, MD, $\mathrm{PhD}^{1,2}$, Eun Ae Park, $\mathrm{MD}$, $\mathrm{PhD}^{1,2}$, and Hyun Ju Chong, $\mathrm{MD}^{3}$

${ }^{1}$ Department of Pediatrics, Ewha Womans University School of Medicine, Seoul, Korea

${ }^{2}$ Ewha Dodam Dodam Center and ${ }^{3}$ Department of Music Therapy, The Graduate School, Ewha Womans University, Seoul, Korea

\section{ABSTRACT}

Purpose: The aim of this study was to evaluate the physiological and behavioral effects of auditory stimulation with their own parent's voice on heart rate and sleep states of very-low-birth-weight infants (VLBWIs) in neonatal intensive care unit.

Methods: The data of 28 VLBWIs at the Ewha Womans University Mokdong Hospital between October 2016 and May 2017 was analyzed. They were exposed to sounds similar to those of mothers' heartbeat they had heard in the uterus and their own parent's voice. Heart rate was assessed as the physiological responses and sleep state of infants as behavioral response. The sleep states were categorized into six states. The music intervention program was provided twice a week.

Results: Twenty-eight babies with an average gestational age of 28 weeks (average birth weight of $1.09 \mathrm{~kg}$ ) had undergone the sessions (average of 16 times) average of 16 times. During the initial period, there were no meaningful differences of the heart rates measured by the physiological functions before and after the sessions. However, as we move to the adaptive phase, the average heart rate was $156.96 \pm 12.22$, and the pre-discharge was 149.11 \pm 12.01 , which indicates meaningful differences $(P<0.05)$. Infants' behavioral function was statistically insignificant.

Conclusion: The music intervention techniques in the neonatal intensive care unit environment in Korea have provided positive influence to VLBWIs' physiological reactions. We were not able to come up with the relevant indicators during this phase of the study but we do plan to announce the future study results after indexing the observation results.

Key Words: Music intervention; Intensive care units, neonatal; Infant, very low birth weight
Received: 18 June 2020

Revised: 10 August 2020

Accepted: 24 August 2020

Correspondence to: Eun Ae Park, MD, $\mathrm{PhD}$

Department of Pediatrics, Ewha Wo mans University School of Medicine, 1071 Anyangcheon-ro, Yangcheon-gu, Seoul 07985, Korea

Tel: +82-2-2650-5574

Fax: +82-2-2653-3718

E-mail: pea8639@ewha.ac.kr

*Ji Yun Yun and Ji Sun Kim contributed equally to this study as first authors.

Copyright(c)

By Korean Society of Neonatology.

All right reserved.

This is an Open-Access article distributed under the terms of the Creative Commons At tribution Non-Commercial License (http:// creativecommons.org/licenses/by-nc/4.0), which permits unrestricted non-commercial use, distribution, and reproduction in any medium, provided the original work is pro perly cited. 
서론

신생아중환자실은 미숙아들에게 모태와 같은 역할을 제공하는 곳이나 이곳에서 지속적으로 듣게 되는 각종 소음과 밝은 빛과 같 은 자극의 노출은 미숙아의 성장발달에 방해가 되는 요소로 작용한 다 ${ }^{1)}$. 특히 타 감각에 비해 청각적 자극은 지속적이며 차단이 어려운 자극이고 미숙아들에게 있어 청각적 자극을 조절하기 위한 능력은 제한적이다 ${ }^{2)}$.

엄마의 뱃속에서 태아는 16 주가 되면 소리의 자극에 반응할 수 있 으며 30-32주가 되면 청각 감각이 완전히 성숙하여 청각에 대한 기 억과 학습이 가능하다 ${ }^{3,4}$. 따라서 미숙아는 외부에서 발생하는 청 각적 자극을 다 흡수하면서도 이를 조절할 수 있는 능력은 형성되 지 않았음을 알 수 있다. 이를 염려하여 미국 소아과학회(American Academy of Pediatrics)는 신생아중환자실 내부의 소음 수준이 45 $\mathrm{dB}$ 보다 더 큰 것을 염려하며 가능한 그 수준을 피해야 한다고 경고 했으며 소음 수준이 시간당 $50 \mathrm{~dB}$ 에서 최대 $70 \mathrm{~dB}$ 를 초과하지 않아 야 한다고 권고하고 있다5).

이러한 소음 환경으로 인해 선진국에서는 이미 20년 전부터 음악 치료가 신생아중환자실에 도입이 되었고 신생아중환자실에서의 음 악치료는 신생아중환자실 소음 환경을 음악적 환경으로 전환하는 일종의 'Masking'의 역할을 하는 것으로 여기서 음악적 환경이란 태 아가 엄마의 뱃속에서 친숙하고 평안하게 들은 소리의 환경을 의미 한다6. 초기의 음악치료 개입은 녹음된 음악을 인큐베이터 안에서 틀어주는 것으로 시작되었는데 주로 엄마 목소리, 엄마나 치료사가 부른 노래, 동요, 자장가, 클래식 음악 및 치료사의 연주를 녹음을 사용하여 미숙아의 행동적, 생리적 반응을 측정하였다. 초기의 연 구에 의하면 녹음된 음악을 들은 미숙아들에게서 수면의 효과, 체 중 증가, 심장박동과 호흡의 안정 및 조기 퇴원의 효과를 입증하였 다고. 또한 미숙아에게 유아용 고무젖꼭지와 자장가(PAL-PacifierActivated-Lullaby)를 이용하여 몸무게 증가 및 영양공급을 향상시 키는 연구가 발표되었는데 유아용 고무젖꼭지에 디바이스를 장치 해서 신생아가 젖꼭지를 빨 때마다 자장가를 들려줌으로 적극적인 빨기 행동을 유도하여 미숙아들의 몸무게와 영양공급을 보다 빠른 시기에 효과적으로 이루어질 수 있도록 강화하는 것이다 ${ }^{10)}$. 이외에 도 미숙아에게 제공된 청각자극은 주로 클래식 음악과 ${ }^{11,12)}$ 자궁 내 의 소리를 첨가하거나 ${ }^{13)}$, 심장박동수 또는 여성의 자장가 노래를 녹 음한 음악 ${ }^{14,15)}$ 이었다.

이에 반해 음악치료가 신생아중환자실에 진행되고 연구되어 발 전되면서 녹음된 음악의 한계점들이 드러나기 시작하였고 특히 녹 음된 음악의 음악 선택 한계가 드러났다 ${ }^{16)}$. 음악 선택은 매우 조심스 럽게 간주되어야 한다. 예를 들면 부드러운 리듬, 서정적인 멜로디, 간단한 화성, 부드러운 음색뿐만 아니라 소리 음색의 복잡함도 피해 야 한다. 또한 녹음된 음악은 고정된 템포, 멜로디, 박자 그리고 여러
종류의 악기 연주가 때로는 신생아들에게 지나친 자극으로 간주 될 수 있다는 경향을 보였으며 신생아 각자가 가지고 있는 고유의 리듬 즉 심장박동과 호흡을 고려하지 않은 일방적인 자극일 수 있다는 연 구들이 발표되면서 라이브(live) 음악에 대한 연구가 부각되어 활발 히 진행되었다 ${ }^{17-19)}$.

녹음된 음악과는 달리 라이브 음악은 청각자극 외에도 다감각적 접근, 예를 들면 접촉, 눈맞춤, 흔들어주는 동작(rocking movement) 등이 가능하고 이때에는 주로 엄마나 아빠가 불러주는 노래, 치료사 의 노래나 연주 등을 사용하여 중재의 역할을 하였닥)

실제로 미숙아들에게 녹음된 엄마의 목소리와 엄마가 직접 노래 를 불러 주었을 때를 비교해본 결과, 엄마가 직접 노래를 불러주었 을 때 미숙아의 호흡이 유의미하게 안정되는 결과를 보였다 ${ }^{20,211}$. 이 렇게 음악치료가 신생아중환자실에 도입이 되어 미숙아들의 신체 적, 정서적 안정과 부모와의 애착과 결속을 위해 많은 연구들이 진 행되었지만, 우리나라의 신생아중환자실에는 음악치료 프로그램이 활발히 이루어지지 않고 미흡한 상태이다. 또한 이제까지의 연구가 대부분 mild/stable condition의 미숙아들을 대상으로 제한되어 진 행되었다.

이에 본 연구에서는 현실적으로 출생률이 높아가는 극소 저체중 출생아를 대상으로 라이브 음악의 장점을 부각하여 미숙아에게 가 장 친숙한 양수 환경의 소리 및 그들 부모의 노래나 자장가를 중재 로 하여 생리적 기능 중에 심장박동수, 행동적 기능 중에서는 수면 상태의 변화를 보고자 한다.

\section{대상 및 방법}

\section{1. 대상}

본 연구는 이대목동병원 신생아중환자실에 출생체중 $1,500 \mathrm{~g}$ 미 만의 극소 저체중출생아로 2016년 10월 1일부터 2017년 5월 31일까 지 입원하였던 아기들의 의무기록을 후향적 분석을 통하여 진행되 었다. 당시 이화 도담도담 부모지원 프로그램이 부모들이 협조하는 경우 그 지원프로그램을 일환으로 신생아중환자실에서 음악치료가 제공되었다. 단, 대상군 환아의 상태가 불안정하거나 여러 가지 시 술이나 검사가 시행되는 경우에는 음악치료를 제공하지 않았다, 또 한 유전적 문제나 염색체 이상, 선천성 기형이 없으며, 생리적 반응 에 영향을 줄 수 있는 약물을 투여하지 않는 경우에만 음악치료가 진행되었다. 환자의 기초 질환과 무관하게 동일하게 제공되었으며 중간에 치료가 중단되어 탈락한 경우를 제외한 최종 음악치료가 종 료된 총 28 명의 환자의 음악치료 자료가 본 분석에 이용되었으며 본 후향적 자료분석 연구는 이화여자대학교 부속 목동병원 임상연구 윤리위원회로부터 승인받았다(EUMC 2019-10-034). 


\section{2. 연구 설계 및 절차}

본 연구는 실제로 들려주는 부모의 목소리, 양수 환경의 소리 중 재가 극소 저체중미숙아들의 생리적인 기능 중 심장박동과 행동적 인 기능 중 수면 상태에 미치는 효과를 확인하기 위한 예비연구이고 2016년 10월부터 2017년 5월까지 환자의 상태가 의학적으로 안정 되었다고 판단된 경우 주 2 회, 퇴원할 때까지 음악 중재치료를 하였 으며, 한 회기에 7-10분, 총 28명으로 신생아중환자실에서 부모 방 문 시간에 진행되었던 증례에 대한 분석이다.

본 연구에서 극소 저체중출생아들을 위한 음악 중재는 음악치료 전문가 1 인에 의해 모두 제공되고 평가되었다. 음악 중재는 태아가 엄마의 뱃속에서 가장 많이 친숙하고 일정하게 들은 소리로서 엄마 양수 환경의 소리를 중재로 양수 흐름을 연상할 수 있는 악기 소리 와 심장박동 리듬을 연상할 수 있는 악기의 소리 및 부모의 목소리 와 부모가 부른 노래를 중재로 28 명의 아기에게 한 회기에 약 10 분 정도 제공하였다. 매번 중재 전에 의학팀에게 대상이 음악 중재가 가능한지의 여부를 확인한 후 진행했으며 시행 전 소음측정기를 사 용하여 $\mathrm{dB}$ 레벨을 측정하여 소음 레벨이 $70 \mathrm{~dB}$ 을 초과하는지를 확 인하였다. 회기 내의 측정은 중재 전 분당 평균값의 심장박동수를 측정하였으며 행동적인 기능 중 수면 상태의 반응을 1분간 10-15초 간격으로 관찰하였다. 인큐베이터의 한쪽 문을 열고 중재가 시작되 고 약 10 분간의 중재가 이루어진 후에 다시 동일한 방법으로 측정하 였다. 이때 이루어지는 음악 중재는 다음과 같다(Figure 1).

\section{1) 부모 노래 중재}

본 연구에서 부모의 목소리로 부른 노래 중재는 엄마가 뱃속 태아 에게 많이 불러 준 노래나 부모가 아기에게 불러주고 싶은 노래 및 부모의 마음을 노래의 가사로 사용하여 진행되었다. 부모가 선택한 노래는 연구자가 노래의 속도, 호흡, 선율 구성 등을 부모가 편안하 게 부를 수 있도록 자장가의 형태로 변화하고 부모가 대상에게 노래 를 불러 줄 때에 연구자가 부모의 등을 손으로 가볍게 $8 / 6,4 / 3$ 리듬 과 안정된 속도를 두드림(tapping)을 통해 부모가 노래의 속도와 페 이스를 유지할 수 있도록 보조하였다. 대상의 상태가 부모가 가슴에

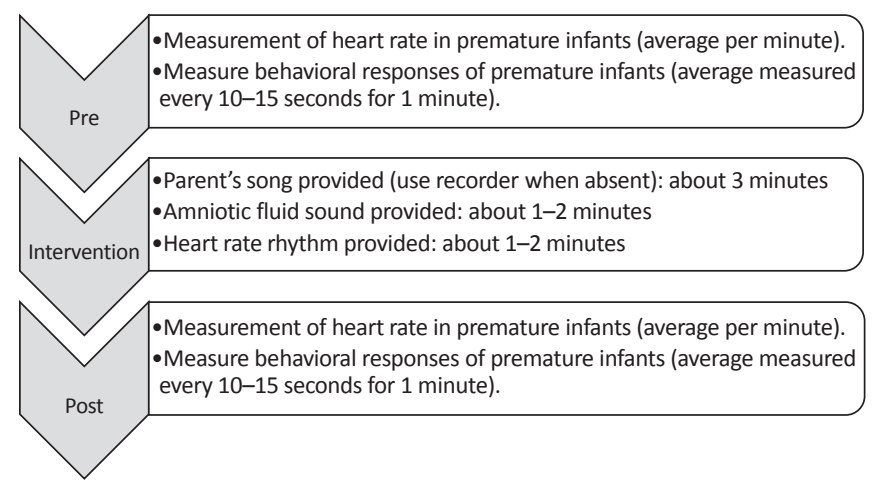

Figure 1. Procedures for providing music therapy in target babies.
안을 수 있으면 안고 노래를 불러주고, 인큐베이터에 있을 경우에 는 인큐베이터 문을 열고 불러주었다. 부모의 노래 제공은 면담 시 에 이루어짐으로 한 곡당 약 3 분 정도의 중재가 이루어졌다. 미숙아 부모가 부른 노래는 부모의 부재 시를 대비하여 내장 스피커를 장치 한 XP-7078G 음성 녹음기를 사용하여 녹음하였고 부모의 부재 시 에 인큐베이터 안 대상의 머리에서 $20 \mathrm{~cm}$ 거리에 위치시켰으며 중 재가 제공되는 동안 자장가의 볼륨은 $60-70 \mathrm{~dB}$ 정도로 유지되었다.

\section{2) 양수 소리 재현}

본 연구에서의 양수 흐름소리는 오션드럼을 사용하여 미숙아에 게 적절한 소리와 강도 및 페이스를 위해 양수 소리를 적용한 선행 연구 6,17 를 참고하였다. 양수 흐름소리의 제공에 사용한 오션드럼은 악기의 한 종류로서 둥근 북 모양으로 그 속에는 작은 구슬로 채워 져 있어 악기를 천천히 움직일 때마다 구슬이 움직여 만드는 소리가 양수의 흐름 소리를 모방한 소리와 같은 소리를 만들어 낸다. 본 연 구에서는 모니터를 통해 대상의 심박수, 호흡 및 산소포화도에 알람 이 울리지 않고 있을 때 오션드럼을 천천히, 부드럽게 움직여서 제 공되는 소리, 강도 및 빠르기가 대상의 심박수와 호흡을 고려하고 과도한 자극이 되지 않게 제공되었다. 양수 소리의 제공은 매회 1-2 분 정도 제공되었다(Figure 2).

\section{3) 심장박동의 리듬 재현}

본 연구에서의 심박 소리는 미숙아가 엄마의 뱃속에서 들었던 안 정되고 예측되며 익숙한 리듬의 제공을 위해 가토박스 악기를 적용 한 선행연구 ${ }^{6,17)}$ 를 참고하였다. 가토박스는 나무로 만든 사각형의 모 양으로 4 가지의 선율을 지닌 악기로서 검지로 한음, 악기가 가지고 있는 음정 중 가장 가까운 minor $3 \mathrm{rd}$ 의 음정과 8 분 음표의 모티브를

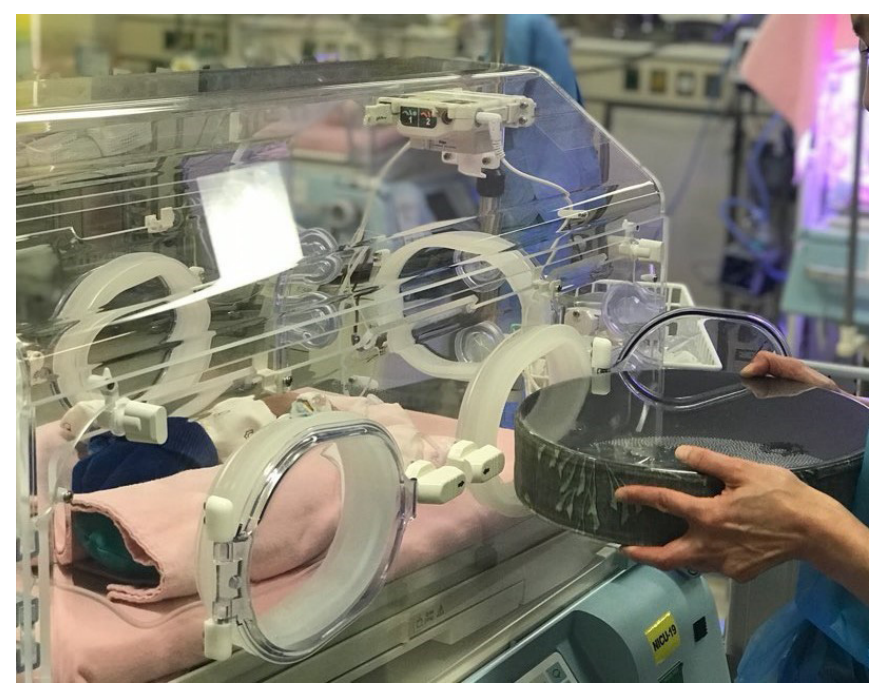

Figure 2. Reproduction of amniotic fluid sound using the ocean drum to babies in an incubator. 
사용하여 반복적이고 지속적이며 안정적인 리듬을 제공하였다. 심 장박동 소리 중재는 대상과 연결된 모니터를 보며 대상의 심장박동 수, 호흡수 및 산소포화도를 고려하여 진행되며 중재 시에라도 모 니터에서 알람이 울리면 중재를 멈추고 알람이 꺼진 후에 다시 중 재를 시작했다. 심장박동 소리 제공은 매회 1-2분 정도 제공되었다 (Figure 3).

\section{3. 연구 평가 도구}

\section{1) 생리적 반응 측정}

본 연구에서는 생리적 반응 중 심박동수를 해당 병원의 신생아중 환자실에서 사용하는 GE neonatal monitoring system (GE Healthcare, Chicago, IL, USA)을 활용하여 분당 심박동수를 음악 중재 시 작 전과 시작 후 1 분간 측정한 평균값을 이용하였다.

\section{2) 행동적 반응 측정}

본 연구에서 행동적 반응 중 수면 상태는 Lester와 Tronick ${ }^{22)}$ 이 고 안한 Neonatal Intensive Care Unit Network Neuro behavioral Scale 을 사용하여 신생아의 수면상태를 세션 시작 전, 후에 10-15초 관찰 로 1 분 동안 측정하였다. 이 행동 반응에 사용된 관찰 도구는 신생 아의 행동상태를 깊은 수면 상태(1점), 가벼운 수면 상태(2점), 졸린 상태(3점), 민활한 상태(4점), 움직임이 많은 상태(5점), 울음 상태(6 점)의 총 6단계로 분류된다. 점수가 낮을수록 미숙아의 행동상태가 안정됨을 의미한다.

\section{4. 자료 분석 방법}

측정된 생리적 반응 및 수면 상태 값은 음악 중재가 첫 도입된 시 점(initial phase, 치료 도입기), 음악 중재가 도입된 횟수의 중앙값 시점(adaptive phase, 적응기), 퇴원을 앞두고 치료가 종료된 시점 (pre-discharge phase 치료 종료기)로 나누어 분석하였다.

수집된 자료는 SPSS WIN program (IBM Co., Armonk, NY, USA) 을 이용하여 분석하였다. 극소 저체중미숙아와 관련된 일반적 특성 은 백분율, 평균 등의 기술통계와 빈도분석을 사용하였고, 연구문제

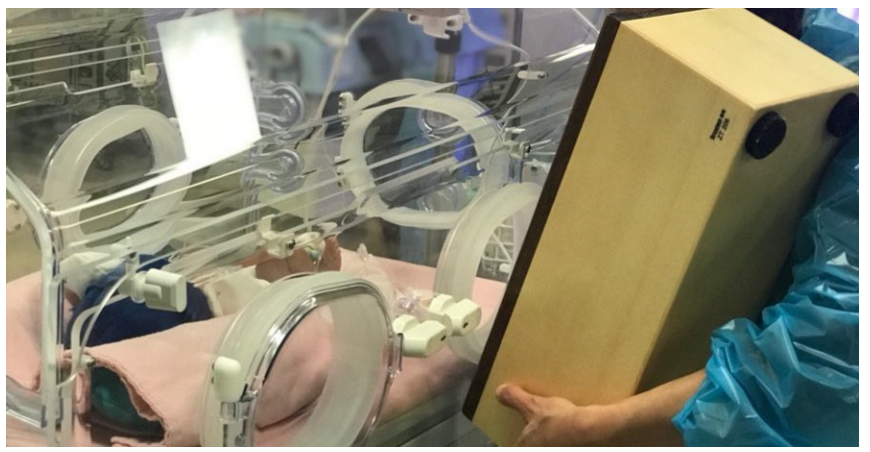

Figure 3. Reproduction of heartbeat sound using the Gato box to babies in an incubator.
를 분석하기 위하여 음악치료 중재 전후의 생리적, 행동적 반응을 Paired t-test로 비교 분석하였다.

\section{결과}

\section{1. 대상의 기본 정보 및 임상적 특성}

대상자의 성별은 남아가 $39.3 \%$, 여아가 $60.7 \%$ 였고 출생 시 재태 연령은 평균 28 주이고 체중은 평균 $1,080 \mathrm{~g}$ 였다. 첫 번째 회기의 시 작은 입원 후 평균 16 일 후에, 병원 후 적응기는 평균 41 일이었으며 퇴원 전 측정기는 평균 64 일이었다. 대상의 $25 \%$ 는 기관지폐이형성 증(bronchopulmonary dyspiasis), 뇌실내출혈(intraventriculuar heorrhage) grade 3 이상 $28 \%$, 미숙아 망막병증(retinopathy of prematurity) grade 3 이상 $14.3 \%$, 신생아 패혈증(cultural proven sepsis) $3.4 \%$ 로 진단되었다(Table 1).

\section{2. 극소 저체중미숙아의 생리적 기능에 대한 음악 중재의 효과} 양수 소리, 심장박동 리듬 및 부모의 목소리 음악 중재 전후 생 리적 기능으로 측정된 아기의 심장박동을 살펴보면, 치료 도입기에 서는 $154.89 \pm 14.49$ 에서 $153.50 \pm 10.44$ 로 감소하였으나 통계적으로 유의미한 차이를 보이지 않았다. 적응기에서는 음악 중재 전 아기 의 심장박동이 $156.96 \pm 12.22$ 에서 중재 후 $152.82 \pm 12.47$ 로 통계적 으로 유의미하게 감소하였다 $(P<0.05)$. 치료 종료기에서도 음악 중 재 전 아기의 심장박동은 $158.29 \pm 17.94$ 에서 중재 후 $149.11 \pm 12.01$ 로 통계적으로 유의미한 차이를 보였다 $(P<0.01)$. 즉, 부모 목소리와 양수 환경 소리가 아기의 심장박동을 낮추어 안정적인 상태로 이끄 는 것으로 나타났다(Table 2).

Table 1. Demographic Characteristics of Study Population

\begin{tabular}{|c|c|c|}
\hline Variable & Results & Range \\
\hline Gestational age (wk) & $28.3 \pm 2.6$ & $22.6-33.2$ \\
\hline Birth weight (g) & $1,080 \pm 260$ & $520-1,490$ \\
\hline Male sex & $11(39.3)$ & \\
\hline Initial measurement (d) & $16(9.0)$ & $5-50$ \\
\hline Adaptive phase measurement (d) & $41(16.8)$ & $16-91$ \\
\hline Pre-discharge measurement (d) & $64(22.1)$ & $31-120$ \\
\hline BPD & $7 \pm 25$ & \\
\hline $\mathrm{IVH} \geq$ grade 3 & $6 \pm 28$ & \\
\hline ROP $\geq$ grade 3 & $4(14.3)$ & \\
\hline Sepsis & $1(3.4)$ & \\
\hline
\end{tabular}

Values are expressed as mean \pm standard deviation or number (\%). Abbreviations: BPD, bronchopulmonary dysplasia; IVH, intraventri cular hemorrhage; ROP, retinopathy of prematurity. 
Table 2. Comparison of Heart Rate Pre and Post-Music Intervention at Each Phase $(n=28)$

\begin{tabular}{lccc}
\hline $\begin{array}{l}\text { Heart rate } \\
\text { (beats/min) }\end{array}$ & Initial phase & Adaptive phase & Pre-discharge \\
\hline Pre & $154.89 \pm 14.49$ & $156.96 \pm 12.22$ & $158.29 \pm 17.94$ \\
Post & $153.50 \pm 10.44$ & $152.82 \pm 12.47$ & $149.11 \pm 12.01$ \\
$P$-value & 0.423 & $0.037^{*}$ & $0.004^{\dagger}$ \\
\hline
\end{tabular}

Values are expressed as mean \pm standard deviation.

${ }^{*} P<0.05 ;{ }^{\dagger} P<0.01$.

Table 3. Comparison of Sleep Score between Pre and PostMusic Intervention at Each Phase $(\mathrm{n}=28)$

\begin{tabular}{lccc}
\hline Sleep score & Initial phase & Adaptive phase & Pre-discharge \\
\hline Pre & $3.28 \pm 1.38$ & $3.57 \pm 1.40$ & $3.46 \pm 1.60$ \\
Post & $3.57 \pm 1.07$ & $3.28 \pm 1.05$ & $2.93 \pm 0.98$ \\
$P$-value & 0.387 & 0.284 & 0.100 \\
\hline
\end{tabular}

Values are expressed as mean \pm standard deviation.

\section{3. 극소 저체중미숙아의 행동적 기능에 대한 음악 중재의 효과}

음악 중재 전후의 행동 반응 중 수면 상태(sleep score)를 살펴 본 결과, 치료 도입기에서 아기의 행동 반응 상태만 $3.28 \pm 1.38$ 에서 $3.57 \pm 1.07$ 로 증가하였고, 적응기와 치료 종료기에서는 아기의 행동 반응 상태가 각각 $3.57 \pm 1.40$ 에서 $3.28 \pm 1.05$ 로, $3.46 \pm 1.60$ 에서 2.93 \pm 0.98 로 음악 중재 이후 감소하였으나 통계적으로 유의미한 차이는 없었다(Table 3). 또한 엄마 양수 환경 소리 중재 후 신생아의 행동 상태를 구체적으로 살펴보면, 깊은 수면 상태, 가벼운 수면 상태, 졸 린 상태의 빈도가 증가하고 민활한 상태, 움직임이 많은 상태, 울음 상태의 빈도가 통계적으로 유의미하지는 않지만, 수치상 감소한 것 으로 나타났다.

고찰

본 연구는 신생아중환자실에 입원한 극소 저체중출생아에게 실 제로 들려주는 부모의 목소리와 양수 환경의 소리 제공이 미숙아의 생리적 기능 중 심장박동과 행동적 기능 중 수면 상태에 미치는 영 향을 규명하기 위한 예비연구이다. 특히, 신생아중환자실에 입원한 환아의 부모가 직접 불러주는 목소리와 자장가 노래를 이용하여 극 소 저체중출생아에게 음악치료를 제공했다는 점이 국내 연구 최초 라 할 수 있다. 본 연구의 주요 결과를 중심으로 한 논의 사항은 다 음과 같다.

첫째, 생리적 기능의 경우, 적응기에서의 음악 중재 전과 퇴원 전 마지막 음악 중재 후, 극소 저체중미숙아의 심장박동에 유의한 차이 를 보였다. 즉 부모 목소리와 양수 환경 소리가 아기의 심장박동을 낮추어 안정적인 상태로 이끄는 것으로 나타났다. 이는 음악 중재가
실제로 엄마의 양수 환경의 소리를 제공하고 미숙아의 생리적 기능 을 고려하여 중재한 연구에에서 실험군이 대조군보다 심박수에 유의 하게 감소한 결과와 유사하며, 실험군 미숙아에게 30분 동안 실제로 연주한 자장가와 대조군에게 녹음된 자장가를 들려준 연구 ${ }^{20)}$ 에서 실험군이 대조군보다 심박수에 유의한 감소를 나타낸 결과와도 유 사하다. 여자의 목소리로 간단하고 지속적이며 반복적인 자장가의 리듬을 살려 불러준 노래를 Eastern drum 반주와 같이 중재한 결과 에 의하면 실험군에서 중재 30분 후에 심박수에 유의한 감소를 나타 낸 선행연구와 맥락이 상통한다. 이에 반해 입원 초기 시기 중재 전 후와 퇴원 시기의 중재 전후에는 유의한 차이가 없었다. 이는 미숙 아들이 엄마 뱃속에서 정상적인 성장이 이루어지지 않은 직후이기 에 다양한 의학적인 테스트와 시술이 이루어짐으로 매회에 세션의 진행이 어려웠고 엄마의 뱃속에서 너무 빨리 분리되어 신생아중환 자실이라는 새로운 환경에 대한 적응에 어려움이 결과에 영향을 미 쳤을 것으로 간주된다. 이에 반해 적응기에는 음악 중재가 좀 더 규 칙적으로 이루어질 수 있었고 시간이 지남에 따라 미숙아가 신생아 중환자실 환경에 적응해가며 안정적인 양상을 보였고, 성숙에 따른 소리에 대한 반응도 민감해짐으로 엄마의 목소리와 배 속 양수 환경 의 소리 제공에 더욱 안정적인 반응을 보인 것으로 간주 된다. 또한, 지속적이고 일관적인 음악 중재가 누적되면서 그 효과가 커졌다고 볼 수 있다.

둘째, 신생아의 행동적 기능 중 수면 상태는 엄마 양수 환경 소리 중재 후 시간이 지남에 따라 안정적인 상태를 보였으나 통계적으로 유의미한 차이가 없는 것으로 나타났다. 구체적으로 살펴보면, 깊 은 수면 상태, 가벼운 수면 상태, 졸린 상태의 빈도가 증가하고 민활 한 상태, 움직임이 많은 상태, 울음 상태의 빈도가 감소한 것으로 나 타났다. 이는 미숙아에게 헤드폰을 귀에 대고 자장가를 20분 들려 준 그룹, 아무것도 들려주지 않고 헤드폰만 귀에 댄 그룹, 대조군 그 룹으로 나눈 연구에서 행동상태 기능 중 수면 상태에 유의한 차이가 없는 결과 ${ }^{23}$ 와 캥거루 케어시, 실제로 연주되는 하프 소리를 중재한 실험군, 캥거루 케어만 중재한 그룹과 대조군으로 나누어 수면 상태 를 측정한 결과 유의한 차이가 없는 결과 ${ }^{24)}$ 와 엄마의 목소리, 녹음된 자장가와 대조군으로 나누어 2주 동안 매일 30분씩 중재 후 수면 상 태를 측정한 결과에도 유의한 차이가 없는 Dorn 등 ${ }^{25}$ 의 선행 연구 결 과와 일치한다. 이는 음악 중재가 부모님 면담 시에 이루어지고 그 시간에는 미숙아들이 부모에게 안겨있거나 부모가 수유 중이라 다 수의 미숙아들이 깨어 있는 상태이므로 수면 상태에 통계적으로 유 의한 차이가 없었으나 시간이 지나 성숙하면서 점진적으로 안정적 인 상태로 도달하는 데 음악 중재가 기여했음을 알 수 있다. 따라서 신생아중환자실에 입원한 극소 저체중미숙아에게 실제로 들려주는 부모의 목소리, 양수 환경 소리 중재가 생리적인 기능 중 심장박동 수와 행동적인 기능 중 수면 상태에 긍정적인 변화가 나타남을 알 수 있었다. 특히 본 연구는 국내의 의료현장의 신생아중환자실에 전 
문적인 훈련을 받은 음악치료사가 부족한 현실에서 음악치료사에 의해 부모의 목소리를 이용한 라이브 음악 중재가 이루어진 연구의 시작으로 그 중요성을 제기하는 의미가 있다. 또한 향후 연구를 신 생아중환자실에 입원한 미숙아들과 그 가족을 위해 확대 연구되어 활용될 수 있을 것이다.

그러나 후향적 예비연구인 본 연구의 제한점과 추후 연구과제는 다음과 같다.

첫째, 본 연구는 일개 3 차 병원의 신생아중환자실에 입원한 극 소 저체중미숙아를 위한 프로그램 중에 하나로서 신생아중환자실 에 입원한 500-1,500 g 미만의 모든 미숙아들에게 음악 중재가 이 루어졌고 환자의 기초 질환이나 중재 시점의 환아 연령 등이 고려 되지 않아 연구의 검증력을 떨어뜨릴 수 있다. 이에 추후에는 대조 군의 선정과 질환에 따른 고려 및 라이브 음악이나 녹음된 음악 중 재 방법의 구별 등 연구 설계를 보강하고 음악 중재 효과의 타당성 과 객관성 및 정확성 확립을 위해 적합한 연구방법을 모색할 필요 가 있다.

둘째, 본 연구는 신생아중환자실에 입원한 극소 저체중미숙아들 의 심장박동수와 수면상태를 알아보기 위해 음악을 중재로 진행되 었으나 추후 후속 연구에서는 심장박동수와 수면 상태 외의 산소포 화도 호흡 및 혈압 등의 다른 생리적인 기능이나 위저류나 $100 \mathrm{cc} /$ $\mathrm{kg}$ 까지의 수유도달 및 체중 증가와 같은 성장과 행동적인 기능에 미 치는 영향으로 확대 연구될 필요가 있다.

마지막으로 본 연구는 신생아중환자실에 입원한 미숙아 부모들 의 참여를 유도하기 위해 초기에 시행 되었던 것으로 차후 부모의 심 리 평가를 통해 음악 중재가 부모와 미숙아의 결속 및 애착 부모 심 리 변화에 어떠한 영향을 미치는지도 연구해 보면 좋을 것 같다.

\section{ARTICLE INFORMATION}

\section{Ethical statement}

This study was approved by the Institutional Review Board of Ewha Womans University Mokdong Hospital (approval number: EUMC 2019-10-034). Written informed consent by the patients was waived due to a retrospective nature of our study.

\section{Conflicts of interest}

No potential conflict of interest relevant to this article was reported.

\section{Author contributions}

Conception or design: E.A.P.

Acquisition, analysis, or interpretation of data: J.Y.Y., J.S.K.,
E.A.P.

Drafting the work or revising: J.Y.Y., J.S.K., S.Y.S., S.J.C., E.A.P., H.J.C.

Final approval of the manuscript: E.A.P.

\section{ORCID}

Ji Yun Yun https://orcid.org/0000-0003-2575-4629

Ji Sun Kim https://orcid.org/0000-0002-0260-4655

Eun Ae Park https://orcid.org/0000-0002-1685-4276

\section{Acknowledgments}

None

\section{REFERENCES}

1. Kang IS, Kim YH. The effect of recorded mother's voice on the body weight and physiological reactions of the premature in fants. J Korean Biol Nurs Sci 2011;13:94-101.

2. Yeum MK, Ahn YM, Seo HS, Jun YH. The effects of maternal heart sound on the weight, physiologic responses and behavioral states of premature infants. Child Health Nurs Res 2010; 16:211-9.

3. Crade M, Lovett S. Fetal response to sound stimulation: pre liminary report exploring use of sound stimulation in routine obstetrical ultrasound examinations. J Ultrasound Med 1988;7: 499-503.

4. Lagercrantz H, Changeux JP. The emergence of human consciousness: from fetal to neonatal life. Pediatr Res 2009;65:25560.

5. American Academy of Pediatrics. Noise: a hazard for the fetus and newborn. Committee on Environmental Health. Pediatrics 1997;100:724-7.

6. Loewy J, Stewart K, Dassler AM, Telsey A, Homel P. The effects of music therapy on vital signs, feeding, and sleep in premature infants. Pediatrics 2013;131:902-18.

7. Caine J. The effects of music on the selected stress behaviors, weight, caloric and formula intake, and length of hospital stay of premature and low birth weight neonates in a newborn intensive care unit. J Music Ther 1991;28:180-92.

8. Shoemark H. Infant-directed singing as a vehicle for regulation rehearsal in the medically fragile full-term infant. Aust J Music Ther 2006;17:54-63.

9. Standley JM. A meta-analysis of the efficacy of music therapy for premature infants. J Pediatr Nurs 2002;17:107-13.

10. Standley JM. The effect of music-reinforced nonnutritive suck ing on feeding rate of premature infants. J Pediatr Nurs 2003, 


\section{8:169-73.}

11. Keith DR, Russell K, Weaver BS. The effects of music listening on inconsolable crying in premature infants. J Music Ther 2009; 46:191-203.

12. Yoo KH. The effects of auditory and vestibular stimulation on stress hormones in preterm infants. J Korean Acad Fundam Nurs 2004;11:203-12.

13. Collins SK, Kuck K. Music therapy in the neonatal intensive care unit. Neonatal Netw 1991;9:23-6.

14. Burke M, Walsh J, Oehler J, Gingras J. Music therapy following suctioning: four case studies. Neonatal Netw 1995;14:41-9.

15. Chou SJ, Choi SH. The effect of music therapy on the heart rate and behavioral state of premature infants. Korean J Child Health Nurs 2006;12:84-8.

16. Haslbeck FB. Music therapy for premature infants and their parents: an integrative review. Nord J Music Ther 2012;21:20326.

17. Charpie M. Music therapy in the NICU a bridge between mother and baby. New York: Satchnote Press, 2002.

18. Loewy J, Hallan C, Friedman E, Martinez C. Sleep/sedation in children undergoing EEG testing: a comparison of chloral hydrate and music therapy. J Perianesth Nurs 2005;20:323-32.
19. Loewy JV. Music therapy for hospitalized infants and their parents. In: Edwards J, editor. Music therapy and parent-infant bonding. Oxford: Oxford University Press, 2011;179-90.

20. Arnon S, Shapsa A, Forman L, Regev R, Bauer S, Litmanovitz I, et al. Live music is beneficial to preterm infants in the neonatal intensive care unit environment. Birth 2006;33:131-6.

21. Garunkstiene R, Buinauskiene J, Uloziene I, Markuniene E. Controlled trial of live versus recorded lullabies in preterm infants. Nord J Music Ther 2014;23:71-88.

22. Lester BM, Tronick EZ. History and description of the Neonatal Intensive Care Unit Network Neurobehavioral Scale. Pediatrics 2004;113(3 Pt 2):634-40.

23. Alipour Z, Eskandari N, Ahmari Tehran H, Eshagh Hossaini SK, Sangi S. Effects of music on physiological and behavioral responses of premature infants: a randomized controlled trial. Complement Ther Clin Pract 2013;19:128-32.

24. Schlez A, Litmanovitz I, Bauer S, Dolfin T, Regev R, Arnon S. Combining kangaroo care and live harp music therapy in the neonatal intensive care unit setting. Isr Med Assoc J 2011;13:3548.

25. Dorn F, Wirth L, Gorbey S, Wege M, Zemlin M, Maier RF, et al. Influence of acoustic stimulation on the circadian and ultradian rhythm of premature infants. Chronobiol Int 2014;31:1062-74. 